\title{
Comparison of non-linearity correction methods for quantitative myocardial perfusion MRI
}

\author{
David A Broadbent ${ }^{1,2^{*}}$, John D Biglands ${ }^{1,2}$, David P Ripley ${ }^{2}$, Sven Plein ${ }^{2}$, David L Buckley ${ }^{1,2}$ \\ From 18th Annual SCMR Scientific Sessions \\ Nice, France. 4-7 February 2015
}

\begin{abstract}
Background
Quantification of physiological parameters, including myocardial blood flow (MBF), by perfusion MRI relies on analysis of data that describes temporal variation of relative contrast agent concentration following bolus administration. At doses required for sufficient SNR, signal enhancement cannot be used directly as the relationship between signal intensity (SI) and the resulting concentrations in blood and myocardium is non-linear. Proposed solutions to this include separation of the AIF and myocardial data acquisition, or model based non-linearity correction.
\end{abstract}

\section{Methods}

A simulated AIF was generated and convolved with a one-compartment (1C) model to generate myocardial data. From these data SI curves were simulated for a conventional saturation recovery (SR) sequence. SI curves were also generated with reduced dose, for a sequence with shorter saturation time (TS) and for a proton density weighted (PDw) sequence with no saturation pulse. Curves were generated assuming a range of saturation pulse efficiencies (SE). Analysis was performed using the following methods and results compared to ground truth. Signal enhancement for full dose myocardial data was analysed using the AIF from both full and reduced dose (dual-bolus), data was converted to $\Delta \mathrm{R} 1$ using methods in the table, and $\mathrm{PDw}$ based conversion was also used with the AIF from the short TS sequence (dual-sequence).

Data from a healthy volunteer processed using the same methods was also examined.

\section{Results}

In simulation results signal non-linearity led to substantial overestimation of MBF when using signal enhancement data from the main bolus only, or underestimation using the dual-bolus method. This was also seen in volunteer data with high (stress/rest MBF $=5.19 / 1.78$ $\mathrm{ml} / \mathrm{min} / \mathrm{ml}$ ) and low $(1.72 / 0.33)$ results for these analyses.

In the simulation study PDw or bookend $\mathrm{T}_{1}$ based conversion eliminated these errors for realistic SE values, and yielded comparable results in vivo (2.98/1.00 and 2.72/ 0.93 respectively). Native $T_{1}$ based conversion exhibited strong SE dependence due to variation of baseline SI with SE, with conversion failure occuring above a threshold over-saturation value. Conversion failure was also observed in volunteer data, consistent with the $1.3 \%$ over-saturation estimated during bookend $\mathrm{T}_{1}$ analysis.

In the simulation data the dual-sequence technique was robust for perfect or under-saturation, but over-saturation of more than around $1 \%$ led to small systematic errors. However, differences between dual-sequence results for the volunteer (1.64/0.69) and PDw or bookend $\mathrm{T}_{1}$ based conversion results were substantially larger than the simulations predicted, and so further investigation is required to understand this discrepancy.

\section{Conclusions}

Application of methods to account for signal non-linearity in myocardial perfusion MRI can be strongly influenced by small imperfections in saturation efficiency and so the robustness of the chosen method should be considered in any study of absolute quantification of perfusion data.

\section{Funding}

David Broadbent is funded by National Institute for Health Research Doctoral Research Fellowship NIHRDRF-2012-05-155. 
Table 1 Model based conversion techniques.

\begin{tabular}{ccc}
\hline & Data Used & Parameter(S) Estimated \\
\hline Native T1 & Pre-contrast T1 \& SI from SR sequence & S0 \\
\hline Bookend T1 & Pre- and post-contrast T1 \& SI from SR sequence & S0 and SE \\
\hline Proton Density & Pre-contrast SI from PDW and SR sequence & Baseline T1 and S0 \\
\hline
\end{tabular}

Data used and parameters estimated in model-based conversion from signal intensity to R1.

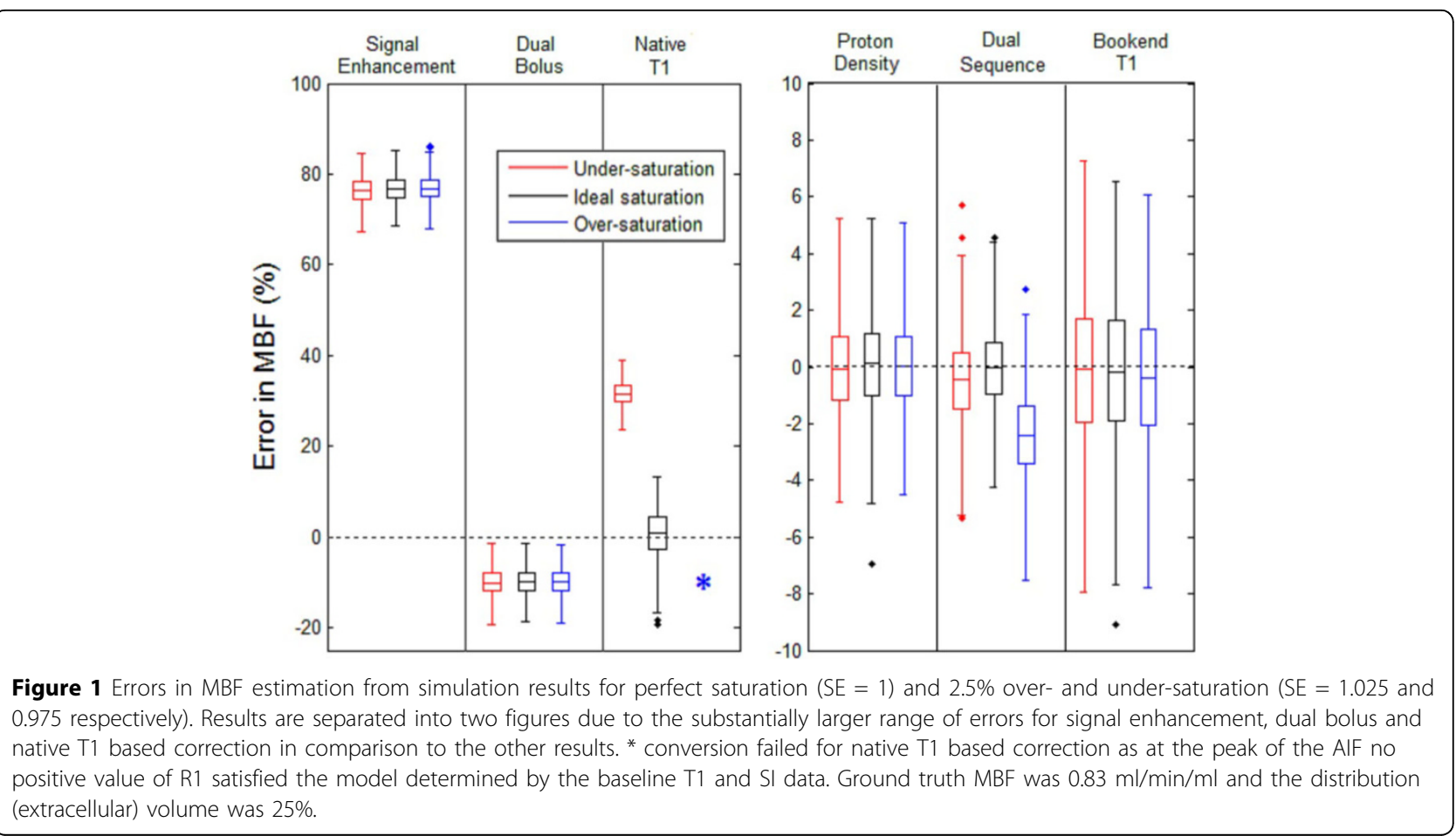

\section{Authors' details}

${ }^{1}$ Medical Physics, University of Leeds, Leeds, UK. ${ }^{2}$ Multidisciplinary

Cardiovascular Research Centre, University of Leeds, Leeds, UK.

Published: 3 February 2015
doi:10.1186/1532-429X-17-S1-P45

Cite this article as: Broadbent et al:: Comparison of non-linearity

correction methods for quantitative myocardial perfusion MRI. Journal of

Cardiovascular Magnetic Resonance 2015 17(Suppl 1):P45.

\section{Submit your next manuscript to BioMed Central} and take full advantage of:

- Convenient online submission

- Thorough peer review

- No space constraints or color figure charges

- Immediate publication on acceptance

- Inclusion in PubMed, CAS, Scopus and Google Scholar

- Research which is freely available for redistribution

Submit your manuscript at www.biomedcentral.com/submit 